\title{
LA TÉCNICA TERAPÉUTICA DE LA MOVIOLA: UNA INTRODUCCIÓN
}

\section{THE THERAPEUTIC TECHNIQUE OF LA MOVIOLA: AN INTRODUCTION}

\author{
María Teresa Miró \\ Universidad de La Laguna. Tenerife, España
}

Cómo referenciar este artículo/How to reference this article:

Miró, M. T. (2019). La técnica terapéutica de la moviola: Una introducción. Revista de Psicoterapia, 30(112), 17-41. https://doi.org/10.33898/rdp.v30i112.282

\section{Resumen}

En el contexto de la psicoterapia, la técnica de la moviola hace referencia a un procedimiento, creado por $V$. F. Guidano, para trabajar con experiencias problemáticas que tienen interés psicoterapéutico como si se estuviera en una sala de montaje cinematográfico. En el texto se presentan algunos principios en los que sefundamenta la técnica y se ilustra su utilización en un caso clínico.

Palabras clave: técnica de la moviola, psicoterapia post-racionalista, narrativa audio-visual

\begin{abstract}
In the context of psychotherapy, the moviola technique refers to a procedure, created by V.F. Guidano, to work with problematic experiences that have psychotherapeutic interest as if they were in a cinema editing room. Some principles upon which the technique is based as well as its use in a clinical case are presented.

Keywords: moviola technique, post-rationalist psychotherapy, audiovisual narrative
\end{abstract}




\section{Introducción}

En sentido genérico, la palabra moviola se refiere a una técnica de edición cinematográfica. Pero, en psicoterapia, cuando se habla de la técnica de la moviola se está haciendo referencia a una técnica terapéutica, creada por Vittorio F. Guidano, para reconstruir experiencias problemáticas como si se estuviera en una sala de montaje cinematográfico. Cuando esta analogía entre el cine y la reconstrucción narrativa de la experiencia vivida se maneja con destreza y conocimiento clínico adecuado, se convierte en una poderosa herramienta terapéutica.

Para poder "editar cinematográficamente" la experiencia problemática de un modo que tenga interés clínico, es necesario partir de una comprensión precisa de la fenomenología y la ecología de la experiencia vivida por el paciente. Guidano, que fue un gran psiquiatra y un gran terapeuta, poseía una importante destreza clínica, proveniente del tratamiento de miles de pacientes en su práctica clínica que, junto con la formación de terapeutas, constituía su trabajo diario. Este saber hacer le permitía guiar la reconstrucción narrativa de la experiencia del paciente en la sesión con maestría y eficacia terapéutica. En sus talleres docentes enseñaba su modelo clínico "post-racionalista", así como su técnica y se refería a ésta como la moviola. Sin embargo, cuando escribía sobre estos temas, no enfatizaba este aspecto. Cuando hizo explícito su método terapéutico en su último libro, "El si mismo en proceso", lo llamó "método de auto-observación". Por un lado, el término "auto-observación" resulta un término clásico en la cultura occidental y cuenta con una importante tradición entre los filósofos; este mismo término fue incluso utilizado por célebres gurús psico-espirituales como G. I. Gurdjieff o P. D. Ouspensky, entre otros. Por otro lado, este término también se ha utilizado para hacer referencia a una técnica de evaluación en el marco de la terapia cognitivoconductual, que es el marco conceptual del que Guidano partió como terapeuta. En este caso, no obstante, esta denominación resulta demasiado genérica, porque no muestra, sino que, en realidad, oculta el carácter cinematográfico que la autoobservación tenía en manos de Guidano.

La técnica de la moviola no fue un punto de partida, sino un punto de llegada en la trayectoria de Guidano. En otras palabras, fue el resultado de sucesivas modificaciones sobre los procedimientos del análisis funcional, proveniente de la terapia de conducta, por un lado, y de los principios de la re-estructuración cognitiva, por otro. Estas modificaciones se llevaron a cabo en un "nicho ecológico cultural" específico, a saber, los años en los que la televisión y el cine penetraron en los hogares. En la vida cotidiana, la pantalla de televisión sustituyó a la mesa familiar.

Además, durante los años 80 , las pantallas de televisión se enriquecieron con los aparatos de reproducción de video. El video ofrecía funciones nuevas que no son propias del cine como tal, sino de su edición o fase de montaje de la película. Estas nuevas funciones permitían detener, ralentizar y acelerar las imágenes hacia delante o hacia atrás. Con estas funciones, las posibilidades de observación de la conducta 
filmada se multiplicaron de un modo enormemente productivo. Como ejemplo de esta extraordinaria productividad, se pueden citar los trabajos de D. Stern (1985/ 1991) y C. Trevarten (2011) sobre la comunicación sincronizada entre los infantes y sus madres. En estos trabajos, minuciosamente se filmaron las interacciones reales de las diadas madre-hijo y el análisis de estas secuencias permitió llegar a una nueva comprensión de los mecanismos subyacentes a la intersubjetividad humana.

Por otro lado, las nuevas posibilidades de la edición de videos se hicieron populares gracias al futbol. En aquellos años, proliferaron los programas de televisión en los que se analizaban a cámara lenta las escenas controvertidas del partido, de modo que los comentaristas deportivos pudieran debatir durante el tiempo que durara el programa sobre si el árbitro se había equivocado o no. (En la actualidad, los árbitros disponen de la posibilidad de volver a ver la jugada problemática sobre la marcha con lo que se conoce como VAR, video-arbitraje o arbitro asistente de video). Pero en los años 80, el VAR todavía no existía. Fue entonces cuando Guidano, que era un gran aficionado al futbol, descubrió que a sus pacientes les resultaba intuitivamente obvio comprender el trabajo terapéutico si utilizaba la analogía del futbol y la herramienta de la moviola. Resultaba fácil explicar que el episodio problemático vivido por el paciente, por ejemplo, un ataque de ira, en cierto modo, resultaba similar a una jugada problemática de un partido de futbol. En ambos casos, en la vida real, los elementos implicados se habían combinado muy rápidamente y resultaba difícil discernir y comprender con claridad lo que había sucedido. Pero ahora, en la seguridad de la sala de terapia, con la ayuda de la moviola terapéutica, era posible analizar o editar cinematográficamente las escenas relevantes para comprenderlas mejor.

Cuando se ve una secuencia filmada a cámara lenta, resulta más fácil apreciar los elementos que la componen, así como su interacción o movimiento. De igual modo, cuando una experiencia problemática, ya sea un ataque de pánico o una discusión con la pareja, se "ve a cámara lenta con el ojo de la mente" -en realidad, se reconstruye con la ayuda del terapeuta- es más fácil darse cuenta de qué ingredientes o mixtura está hecha y cuál ha sido su movimiento o desenlace. Si esta reconstrucción se lleva a cabo con un nivel suficiente de destreza por parte del terapeuta durante la sesión, aumenta la probabilidad de que el paciente sea capaz de reconocer los elementos problemáticos en su experiencia a medida que suceden. Así, puede ir aprendiendo a manejar su experiencia de otro modo. La ralentización de las imágenes es una de las posibilidades de la moviola; pero no es la única. Como en toda reconstrucción narrativa, cuando se trabaja con la moviola, el ritmo es crucial, así como el interés clínico de las escenas a reconstruir. Éstas deben elegirse con cuidado y deben contener las emociones problemáticas bajo estudio. En último término, la clave al utilizar la técnica de la moviola reside en guiar la reconstrucción de la experiencia vivida de forma que el paciente aprenda a aprender de su experiencia. En la segunda parte de este trabajo, se presentará una ilustración de este tipo de trabajo en un caso clínico. 
Las dificultades a la hora de ayudar al paciente a reconstruir la narración de la experiencia problemática de un modo cinematográfico no suelen provenir de los aspectos técnicos. La analogía en la que se fundamenta la técnica se suele entender con facilidad. Además, el manejo de los videos está enormemente extendido en la vida cotidiana actual. Las dificultades tienen que ver con que el terapeuta guie correctamente al paciente en la reconstrucción minuciosa de la experiencia vivida, de modo que le ayude a comprender sus propias reglas de funcionamiento, es decir, sus gestos automáticos, sus sesgos cognitivos, sus reglas aprendidas, etc. También es importante saber cuándo se puede hacer una reconstrucción de este tipo, en profundidad. Por ejemplo, en casos de estrés post-traumático no estaría indicado utilizar la moviola antes de que el paciente disponga en su repertorio de suficientes recursos para estabilizar la posible reactividad neurovegetativa.

En la primera parte de este trabajo, se presentarán los conceptos básicos de una concepción fenomenológica, "enactiva" y ecológica del conocimiento y la conciencia humana. Desde ella, se abordará la doble perspectiva del cuerpo como sujeto y como objeto, así como las nociones de autoconciencia pre-reflexiva y reflexiva. Estas nociones resultan centrales para comprender el exceso de autoconciencia o autoconciencia hiper-reflexiva como una dimensión unitaria que resulta transversal a muchas patologías y que es también una condición de la cultura post-moderna (Pérez Álvarez, 2012; Sass, 1992/2014). Este exceso de autoconciencia podría ser corregido con una terapéutica transversal como las Intervenciones Basadas en Mindfulness. En último término, estos aspectos estarían relacionados con las vertiginosas transformaciones culturales que está sufriendo la conciencia humana en la actualidad, debidos a la comunicación electrónica, la revolución digital y a lo que se empieza a llamar ya la Cuarta Revolución Industrial.

Pero antes de entrar en los temas de la cognición encarnada y la autoconciencia pre-reflexiva, conviene recordar los orígenes de la técnica de la moviola dentro de la trayectoria profesional de Guidano.

\section{Orígenes de la técnica terapéutica de la moviola}

La técnica de la moviola puede ser vista como el resultado de sucesivas modificaciones en los métodos del análisis funcional propios de la terapia de conducta, por un lado, y de la re-estructuración cognitiva propia de la terapia cognitiva, por otro, como se mencionó anteriormente. Para presentar esta perspectiva, no obstante, conviene empezar contrastándola con la visión, popular y estándar hoy en día, que presenta la evolución de la psicoterapia científica en tres etapas: la primera etapa sería la de la terapia de conducta basada en el condicionamiento operante y el condicionamiento clásico, que comenzó en los años 50 y 60, la segunda comprendería las terapias cognitivas, que florecieron en los años 70 y 80 , y la tercera haría referencia a lo que se presentaba como terapias de "tercera generación", como el enfoque de la Terapia de Aceptación y Compromiso (ACT) y las Intervenciones Basadas en Mindfulness (IBM) entre otros, a finales de los años 
90 y sobretodo a partir del 2000 (Hayes, 2004).

En contraste con esta visión de la evolución de los tratamientos psicológicos, Guidano (1990) ofreció una visión interna, desde dentro, es decir, como participante implicado en la construcción de una psicoterapia científica, comenzando como practicante de la terapia de conducta. Esta visión fue presentada en un texto publicado en la Revista de Psicoterapia en 1990 con el siguiente título: "De la revolución cognitiva a la intervención sistémica en términos de complejidad: la relación entre teoría y práctica en la evolución de un terapeuta cognitivo". Este texto es la versión escrita de una conferencia que impartió en la Sociedad Italiana de Terapia Cognitivo Conductual, de la que había sido socio fundador y primer presidente. Así, el propósito del texto no es otro más que explicar a los colegas y discípulos cómo y porqué pasó de la terapia de conducta a la terapia cognitiva, para terminar en lo que entonces llamaba intervención sistémica en términos de complejidad y que más tarde, en su obra escrita, adquirió el nombre de terapia cognitiva post-racionalista. No obstante, como intentaremos mostrar a continuación, por debajo de todos estos nombres o marcas de terapia, hay algo que no cambia, a saber, una forma minuciosa y no-abstracta de construir la situación terapéutica para facilitar el autoconocimiento del paciente, con el tiempo este trabajo adquirirá forma de moviola cinematográfica.

En el mencionado artículo, Guidano narra cómo se adhirió, al comienzo de su carrera, a una férrea disciplina de observación psicoterapéutica basada en el método científico, dentro del marco conceptual de la terapia de conducta. A partir de los principios del condicionamiento clásico y del operante, el comportamiento humano podía ser visto como una máquina de precisión regulada por las contingencias ambientales. Así, el comportamiento de un paciente con agorafobia, por ejemplo, podía ser visto como una secuencia de conductas de evitación frente a las situaciones temidas que se mantenían en el tiempo debido al valor reforzante del alivio de la aversión (condicionamiento operante). A la vez, se entendía que las situaciones temidas habían adquirido su carácter atemorizante, porque se había establecido una conexión cronológica con perturbaciones anteriores espontáneas (condicionamiento clásico). A partir de esta concepción del trastorno, en la sesión clínica, el terapeuta guiaba el análisis funcional de las situaciones temidas realmente vividas por el paciente. Por ejemplo, se invitaba al paciente a relatar el último "ataque" de agorafobia sufrido. Pero este relato no podía hacerse de cualquier modo, es decir, no podía dejarse en manos del libre albedrío del paciente. De hecho, gran parte de lo que sucede en terapia -en cualquier terapia-consiste en que el paciente aprende a narrar su experiencia de otro modo y, por esta vía, aprende también a relacionarse con ella de otro modo.

En la práctica de la terapia de conducta con el ejemplo que nos ocupa, de un modo cuidadoso, respetuoso y cordial a la vez, Guidano reconducía la narración del episodio para que el paciente pudiera observar con claridad su propio comportamiento de manera objetiva, tal como se había producido en la situación vivida. Este 
aspecto resultaba crucial a la hora de llevar a cabo el análisis funcional, pues su propósito último era hacer visibles las conexiones estímulo-respuesta o respuestarefuerzo, de modo que el paciente pudiera hacerse consciente de cómo estas conexiones "automáticas" guiaban su comportamiento. Al guiar esta observación, el terapeuta buscaba un punto de observación lo más objetivo posible. En la práctica, esto significaba que se invitaba al paciente a verse desde fuera, como si fuera un actor.

Volviendo al caso de agorafobia, una vez establecida la secuencia problemática tal como se producía en la realidad por medio del análisis funcional, se estaba en condiciones de abordar la exposición gradual in vivo (o en imaginación primero, según la gravedad del caso). De este modo, gracias a la exposición, se iba debilitando el circuito auto-reforzante entre evitación y alivio de la ansiedad. Junto a las técnicas de exposición, la terapia de conducta ha contado también con otras muchas herramientas o técnicas para modificar la conducta. De todas ellas, tal vez la más investigada haya sido la "desensibilización sistemática", en la que se instruye al paciente a sumergirse gradualmente (en la imaginación primero) en las situaciones temidas, mientras se encontraba en un estado de completa relajación, que resultaba antitético con la ansiedad. Aquí también, en la medida en que se invitaba al paciente a imaginarse a si mismo en la situación temida, se facilitaba que aprendiera a verse desde fuera, como si fuera un actor. De hecho, este aprendizaje es común a todas las estrategias de la terapia de conducta. En otras palabras, que el paciente aprenda a verse a si mismo desde fuera por medio de la terapia, es la contrapartida lógica de que el terapeuta comprenda su trastorno o problema desde el punto de vista de la conducta. En último término, aprender a verse desde fuera lleva consigo mayor auto-control, mayor auto-regulación y mayor autoconocimiento, debido a que inevitablemente el paciente se hace más consciente de cómo se siente, así como de la información que transmite a los demás.

Siguiendo a Guidano (1990), no fueron los resultados terapéuticos los que motivaron la crisis del conductismo. Éstos seguían siendo buenos y con frecuencia se producían en pocas sesiones, de modo que la práctica del análisis funcional, que implica el análisis de secuencias de conductas como acabamos de mencionar, se ha mantenido, de un modo u otro, hasta el presente. Guidano (1990) opinaba que lo que acabó con el conductismo fueron las discrepancias entre los resultados y el pobre poder explicativo que los principios del condicionamiento ofrecían a la hora de comprender los cambios terapéuticos o sus excepciones.

También se podría decir que lo que sucedió fue que, en los años 70 , gracias al desarrollo de las tecnologías de la computación y los ordenadores, junto con el desarrollo paralelo de la teoría de la información y la cibernética, la psicología científica fue penetrando en lo que hasta entonces se había denominado "la caja negra". En otras palabras, la perspectiva de la psicología básica científica se fue abriendo paso en el estudio del lenguaje, así como en el estudio de los procesos del pensamiento, la imaginación y la resolución de problemas. Estos estudios permitie- 
ron la emergencia de una nueva forma de ver al ser humano como un procesador de información, en lugar de como un ser hedonista manejado por premios y castigos. Así como un computador procesa información en función de un programa, de igual modo los seres humanos procesan (o distorsionan) la información en función de esquemas cognitivos o creencias aprendidas. Cuando esta forma de pensar se aplicaba a la situación terapéutica, cambiaba el foco de atención de la estrategia terapéutica: ahora el aspecto clave a investigar residía en averiguar la estructura jerárquica del sistema de creencias del paciente, para proceder a su progresiva reestructuración cognitiva. Pero ¿cómo se procedía a investigar el sistema de creencias del paciente, en la práctica?

En la psicoterapia cognitiva, los métodos para investigar los sistemas de creencias no son uniformes. Es posible apreciar diferencias entre los procedimientos que utilizaba A. Ellis (1961/2017) de los que utilizaba A. T. Beck (1976), por ejemplo. No obstante, todos los procedimientos cognitivos persiguen un mismo objetivo: instruir al paciente a observar sus pensamientos o lo que algunos conductistas (como J. Cautela) llamaron conductas encubiertas. Estos aspectos internos pueden tener la forma de imágenes mentales o de un diálogo verbal interior o de pensamientos automáticos o incluso de creencias irracionales, en función de la teoría a la que se adscriba el terapeuta. En cualquier caso, se trata de aspectos que el paciente aprende a reconocer en la sesión terapéutica con la ayuda del terapeuta, y después poco a poco los aprender a discriminar en su experiencia. Este aspecto es muy importante porque, aunque la terapia cognitiva trabaja con aspectos de la experiencia interna del paciente, la auto-observación que se enseña no es de tipo introspectiva. No se trata de mirar dentro como si hubiera algo que ver, es decir, como si lo que hubiera que ver ya estuviera ahí, como si fuera algo sustancial. Al contrario, en la sesión terapéutica, se procede a la reconstrucción de experiencias vividas concretas, a partir de las cuales se le ayuda al paciente a focalizar la atención en sus sensaciones corporales, su experiencia emocional, así como sus pensamientos verbalizados o silenciosos, tal como surgen en la sesión al re-examinar la situación vivida. Al llevar a cabo este trabajo, es muy importante que el terapeuta respete el ritmo interno del paciente y permita que los significados sentidos emerjan desde dentro, porque sólo así pueden ser vividos por el paciente como algo propio con valor de evidencia, en lugar de la mera persuasión externa.

En los enfoques clásicos de la terapia cognitiva, como el de A. T. Beck, la labor del terapeuta se centra principalmente en corregir las distorsiones cognitivas que subyacen al trastorno siguiendo la teoría cognitiva. No obstante, en la forma de trabajar de Guidano, el terapeuta renunciaba a este papel de persuasor o garante del orden establecido. En su lugar, la relación terapéutica se entendía como una relación al servicio de la exploración personal del paciente de sus propias reglas de funcionamiento - verdadero objetivo de la terapia en el modelo de Guidano. Este aspecto es relevante, pues sólo si la relación terapéutica es una relación real, la perspectiva personal de la primera persona puede tener fuerza y realidad. 
En el artículo que estamos comentando, Guidano (1990) no se detiene en los aspectos técnicos del procedimiento terapéutico. Los da por supuesto o por sabidos. Se limita a la discusión de los fundamentos teóricos de las estrategias terapéuticas. También señala que en su práctica clínica la fuente principal de discrepancias entre la práctica y la teoría que le llevó a seguir buscando un modelo más integrador provenía del hecho de que las relaciones personales que jugaban un papel crucial en numerosos casos ilustrados en el texto, sin embargo, carecían de función y no podían ser adecuadamente explicadas ni por la terapia de conducta, ni por la terapia cognitiva clásica. En último término, como ilustra la trayectoria de Guidano, fueron los aspectos relacionales, en su creciente complejidad, los que no encontraron acomodo ni en la terapia de conducta, ni en la terapia cognitiva. En las llamadas terapias de tercera generación de corte conductista se ha intentado corregir este aspecto y se asigna un papel central a las cuestiones relacionales.

Cuando se dio cuenta de que había que ir más allá del enfoque empirista que permeaba los enfoques ya transitados, Guidano comenzó a explorar el "paradigma de la complejidad", que había sido introducido por la "segunda cibernética" dentro del enfoque sistémico. Con este paso, se introducía al observador dentro del sistema. Esta exploración, que en el trabajo comentado denominaba "intervención sistémica en términos de complejidad", dio lugar a su libro "Complexity of the self" (Guidano, 1987). En este texto, se narraba la "búsqueda de un modelo unitario y evolutivo de la psicopatología humana llevada a cabo desde dentro de la perspectiva de un enfoque sistémico orientado a los procesos hacia la complejidad organizada" (pág. xi). En su época este texto no contó con un público entusiasta. Es posible pensar que el texto resultaba complejo y que la concepción que proponía era demasiado sistémica para los terapeutas cognitivos y demasiado cognitiva para los terapeutas sistémicos. Además, el compromiso de Guidano con el enfoque científico, específicamente con una visión naturalista de la cognición, tanto como su rigor metodológico, hacía que el lenguaje de sus textos fuera difícil de leer y asimilar. Tampoco se dejaba traducir a los conceptos ya existentes, ni daba lugar a hipótesis concretas empíricamente contrastables, con las que los profesores universitarios pudieran avanzar sus carreras. No obstante, en su obra póstuma, escrita y editada por el profesor Quiñones a partir de un seminario, este carácter difícil del estilo de Guidano ha sido corregido y el texto denominado "El modelo cognitivo postracionalista. Hacia una reconceptualización teórica y clínica", ha contado con numerosas re-ediciones en Italia y en su versión española ha vuelto a ser re-editado recientemente (Guidano y Quiñones, 2001/2018). Por otro lado, también sería posible pensar que, en esta fase central de su obra, en los textos de 1987 y 1991, Guidano se adelantó a su tiempo, especialmente con su concepción de las organizaciones de significado personal. Un enfoque similar a éste está emergiendo con fuerza en la actualidad como un intento de superar la visión simplista y a-teórica implicada en los manuales estadísticos de la psicopatología tipo DSM. Nos referimos al texto denominado: El Marco de Poder, Amenaza y Significado: hacía 
la identificación de patrones en el sufrimiento emocional, las experiencias inusuales y el comportamiento perturbado o perturbador como alternativa al diagnóstico psiquiátrico funcional (para abreviar Marco PAS) (Johnstone et al., 2018). (Este texto ha sido publicado por la Sociedad Británica de Psicología Clínica y se encuentra disponible en Internet, en formato abreviado y en formato extendido; también ha sido traducido al español por la Asociación Española de Neuropsiquiatria, AEN).

\section{Parte I, Teoría: Conocimiento, Realidad y Ficción}

En este apartado abordaremos los conceptos teóricos relevantes para comprender la técnica terapéutica de la moviola. Estos conceptos se enmarcan en una concepción fenomenológica y ecológica del conocimiento y la conciencia (Fuchs, 2018). A su vez, esta concepción se fundamenta en una comprensión corpórea y enactiva de la cognición y el conocimiento, enraizada en el mundo de la vida (Varela, Thompson y Rosch, 1991/2017). Estas ideas resultan relevantes para poder entender una cuestión muy importante a la hora de trabajar con la moviola, a saber, que el cuerpo posee un doble aspecto: como un cuerpo vivido o subjetivo, por un lado, y como un cuerpo viviente y objetivo, por otro. Además, en relación a la concepción ecológica de la cognición y la conciencia que se explora en esta parte teórica, se abordan aspectos de la nueva ecología creada por las nuevas tecnologías de la comunicación, denominada en inglés media ecology. La moviola hace uso de estos aspectos tecnológicos, en el sentido en que utiliza la metáfora del cine como una herramienta para facilitar el trabajo terapéutico. En este sentido resulta relevante comprender el juego de perspectivas entre realidad y ficción que, como veremos, se pone en juego a la hora de ver una película, así como, en general, en la contemplación de una obra de arte, el como si del mundo del arte. Esta capacidad de actuar como si, que forma parte de la contemplación artística y también de la empatía, resulta muy relevante en nuestro mundo actual, debido a la arrolladora presencia de los medios de la comunicación electrónica a partir de la revolución digital. En la actualidad, y de un modo increíblemente acelerado, la comunicación está cada vez más y más mediada por aparatos tecnológicos y pantallas digitales. La comunicación cara a cara está dejando paso a ambientes virtuales, en los que la realidad se experimenta como series infinitas de símbolos digitales que fluyen por la pantalla, como se planteaba en la película Matrix. Si en lugar de interactuar cara a cara con seres humanos de carne y hueso, se pasa cada vez más tiempo interactuando con otros virtuales sólo presentes a través de los medios, ¿cómo va a evolucionar nuestra empatía?, ¿cómo se van a ver afectadas nuestras emociones? No es difícil darse cuenta de que esta nueva situación supone una alteración radical de las condiciones fundamentales en las que la evolución humana ha tenido lugar (ver Harari, 2018). 


\section{El conocimiento encarnado}

En el mismo año en que apareció publicado el texto de V. Guidano "The self in process. Toward a post-rationalist cognitive therapy", 1991, se publicó también "The embodied mind. Cognitive Science and Human Experience" de F. Varela, E. Thompson y E. Rosch. Esta coincidencia es interesante porque ambos textos toman como punto de partida la epistemología evolutiva y el enfoque sistémico. F. Varela, junto con $\mathrm{H}$. Maturana, había sido pionero en proponer el fenómeno de la autopoesis como la emergencia original de una cognición rudimentaria en la vida. Desde esta perspectiva, se podía concebir la autonomía de los organismos vivos e, incluso, se podía plantear la existencia de una continuidad entre la vida y la conciencia. La evolución de la vida, en realidad, es un proceso de auto-conocimiento.

La auto-organización de los seres vivos se comprende como una red de procesos interconectados y articulados en múltiples niveles de interacción, sujetos a una causalidad circular. Así, el ser humano se podía comprender como un sistema autónomo y auto-organizativo que con su actuar o, como diría Francisco Varela, con su enacción da sentido $\mathrm{u}$ otorga un significado al mundo en que vive $\mathrm{y}$, al hacerlo, a la vez, se produce a sí mismo.

La consecuencia más importante de esta perspectiva residía en que los procesos cognitivos no eran vistos como "representaciones" de una realidad externa e independiente del organismo. Por el contrario, se entendían como estructuras constitutivamente dependientes de patrones sensorio-motores de percepción y acción. En un circuito de influencia mutua, se produce un acoplamiento sensoriomotor entre el organismo y su ambiente. Así, dentro de este marco, el mundo deja de ser algo externo, pre-especificado e internamente representado, y pasa a ser concebido como un ámbito relacional actuado (enacted) o hecho posible por la forma en que el organismo se acopla con el ambiente. Se entiende que un sistema es adaptativamente autónomo en la medida en que se genera y se mantiene a si mismo por medio del cambio estructural y funcional constante. En consecuencia, un sistema cognitivo autónomo no puede ser adecuadamente definido desde el exterior en términos de entradas y salidas. Es necesario tener en cuenta su experiencia en el mundo de la vida.

A la vez, dentro del marco de la auto-organización de la vida, no existe un punto de apoyo externo que pueda servir de fundamento o anclaje. La actividad mental como proceso auto-organizativo es entendida como un conjunto de procesos emergentes constantemente cambiantes que surgen dentro de un complejo sistema que comprende tanto al cerebro como al resto del cuerpo y al ambiente físico y social. Cuando se comprende este proceso, se comprende también que no existe un agente o selfúltimo que controle el proceso de auto-organización. Y ¿qué significa esto a la hora de comprender o relacionarnos con nuestra experiencia personal?

Caben varias opciones: Por un lado, cabe la opción de entender el propio proceso auto-organizativo como una proceso dialéctico entre un self sujeto (un yo) y un self objeto (un $m i$ ), utilizando la terminología introducida por W. James (1890/ 
1994). Esta es la opción que exploró Guidano y sobre ella articuló una teoría de la psicopatología (Guidano, 1987) y también de la psicoterapia (Guidano, 1991). En último término, esta opción no cuestiona, ni va más allá del dualismo observadorobservado. Lo que hace es constituirla dialécticamente como un circuito autoorganizativo, cerrado en su auto-referencia constante. En términos psicopatológicos, esta auto-referencia constante no resulta muy diferente de lo que otros autores han denominado hiper-reflexividad (Pérez Álvarez, 2012). La metodología seguida por Guidano ha sido interesante y fructífera para comprender la psicopatología y, en la medida en que se comprenden los circuitos patológicos, se puede guiar mejor la reconstrucción terapéutica. Sin embargo, resulta difícil ver cómo escapar a la autoreferencia constante. En otras palabras, si lo que organiza la identidad personal del sistema es la dialéctica entre el "yo" (experiencia inmediata) y el "mi" (imagen de si) y si ésta dialéctica se centra en mantener una imagen aceptable de uno/a mismo/ a a toda costa, entonces el exceso de autoconciencia parece garantizado. El camino hacia la hiper-reflexividad queda abierto. Autores como Sass (1992/2014) y Pérez Álvarez (2012) sostienen que éste ha sido, en efecto, el camino al que ha conducido el exceso de conciencia de si que se introdujo con la modernidad. También hay autores como McLuhan (1964) que han sostenido que esta focalización excesiva en la cuestión de la identidad personal es un sub-producto de la tecnología de la imprenta. Nos convertimos en aquello que contemplamos - pensaba McLuhan. De este modo, la lectura de novelas habría contribuido a poner en primer plano la cuestión de la identidad personal - el s. XIX fue el siglo de la novela. Siguiendo este razonamiento, habría que preguntarse por el sentido de la cuestión de la identidad personal en un marco tecnológico en el que es posible tener 20 perfiles o los que uno quiera, a la vez. En otras palabras, si puedo tener varios perfiles públicos a la vez, en Facebook, por ejemplo, ¿qué sentido tiene preguntarse por cuál de ellos me representa a mi como si hubiera algo que pudiera ser representado? Con estas afirmaciones no se está sosteniendo que la cuestión de la identidad personal no sea relevante; al contrario, como Guidano sabía y como veremos después, el exceso de autoconciencia constituye la vía regia a las formas psicopatológicas. Lo que se está afirmando es que en el contexto "liquido" de las pantallas actuales la cuestión de la identidad se plantea de un modo distinto del modo en que lo hacía en el mundo literario de las formas impresas que permanecen.

Valera, Thompson y Rosch (1991) exploraron una opción diferente a la de Guidano. Ésta opción consistió en tomar en serio la visión budista de anatta o (noself) de que no existe, en realidad, un selfúltimo, en ningún sentido individualista. No es lo mismo articular el self como una dialéctica entre el yo y el mi, que sostener que el self como imagen de mi (el self como objeto) no tiene realidad alguna - salvo la efímera y vacua realidad de un pensamiento. Esta última opción, es la opción congruente con la tecnología "liquida" de la pantalla presente en el mundo actual. Probablemente por esta razón, la filosofía budista está teniendo una expansión sin precedentes en nuestros días. En lugar de un self, el pensamiento budista afirma el 
origen co-dependiente de los fenómenos que, en realidad, no es sino un camino de autoexploración. Vivir implica ser consciente. Somos en la conciencia que, en último término en sentido budista, no es individual y trasciende la dualidad sujetoobjeto. Profundizar en el examen de la no-dualidad, no obstante, queda más allá del propósito de estas páginas. En el texto mencionado, para hacer referencia al vértigo al que nos lanza la conciencia de falta de fundamento último externo a nosotros mismos, se citan con frecuencia los versos de Antonio Machado: "Caminante no hay camino/se hace camino al andar/Al andar se hace camino/ $Y$ al volver la vista atrás / se ve la senda que nunca se ha de volver a pisar".

La práctica de mindfulness (o mindful awareness) es la vía que se propone en "The embodied mind" para hacerse cargo plenamente de que se hace camino al andar. Esta práctica ancestral, de origen budista, ha tenido un crecimiento exponencial durante los últimos años, porque se ha mostrado útil para afrontar problemas como el estrés, la ansiedad y la depresión, que han alcanzado proporciones endémicas tras la revolución digital (Miró, 2012). Además, profundizar de un modo disciplinado en el conocimiento de la conciencia que somos ayuda a disolver la dualidad fundamental observador-observado, así como las fronteras rígidas del si mismo o el egocentrismo basado en el contraste de nosotros versus ellos. Por esta razón, la práctica de mindfulness se está extendiendo como la pólvora en el mundo actual.

Por último, para cerrar este epígrafe vale la pena mencionar que el texto de Varela, Thompson y Rosch (1991) ha sido reconocido como un texto muy inspirador para muchos investigadores, desde el campo de la robótica a la neurociencia cognitiva o los estudios sobre el Dharma. Esto explica que fuera re-editado en 2017, con dos introducciones nuevas de E. Thompson y E. Rosch. Estos autores, que han seguido desarrollando la perspectiva enactiva después de la muerte de F. Varela en 2001, exponen en sus textos una visión crítica de lo sucedido en estos 25 años. Esta nueva re-edición también cuenta con un prólogo de J. Kabat-Zinn, probablemente el autor más influyente en la expansión de mindfulness tanto en el ámbito social, en general, como en los tratamientos psicológicos en particular).

\section{Auto-conciencia pre-reflexiva y autoconciencia reflexiva}

Los seres humanos no sólo estamos en el mundo, sino que también somos conscientes de estar en el mundo y de nosotros mismos estando en el mundo. Es decir, somos conscientes de percibir un mundo $\mathrm{x}$ y también de nosotros mismos percibiendo x. Ahora bien, del hecho de que seamos conscientes de ambas realidades, no se sigue que seamos conscientes de ambas del mismo modo. Por lo general, en la vida cotidiana, en el mundo en el que estamos junto a los demás, somos conscientes focalmente de las tareas, imágenes, palabras o lo que sea $\mathrm{x}$, mientras que sólo somos conscientes subsidiariamente de nosotros mismos. Esta distinción entre focal y subsidiario, utilizada por M. Polanyi (1958), es similar a la distinción figurafondo establecida por los psicólogos de la Gestalt. Por ejemplo, al clavar un clavo en la pared, de una manera tácita y subsidiaria se integran el conjunto de elementos 
relevantes (la postura de mi cuerpo, la distancia a la pared, agarrar el martillo, sostener el clavo entre los dedos, la coordinación de la mano, el ojo y el movimiento de la mano, etc.) al llevar a cabo la acción. Esta integración es tácita, es decir, que todos los elementos implicados se ordenan armónicamente sin que ello requiera la atención focal que está situada en sostener el clavo y golpear correctamente con el martillo sin magullarse los dedos al hacerlo. Sucede lo mismo al aprender a montar en bicicleta o al aprender y desempeñar cualquier otra actividad o destreza. Esta conciencia tácita que tenemos del cuerpo al vivir y al hacer lo que hacemos, que es subsidiaria y no problemática, es también lo que en el marco de la fenomenología se denomina autoconciencia corporal pre-reflexiva.

La conciencia corporal pre-reflexiva se denomina también conciencia corpórea subjetiva. Frente a otras concepciones, como la de G. H. Mead (1934/1968), en esta visión actual de la conciencia fenoménica, el énfasis recae en el papel del cuerpo. Se es consciente de uno/a mismo/a en el vivir, porque se es consciente del propio cuerpo como vehículo o puerta de los sentidos (o mejor de la unidad sensorio-motora). Como ya se ha comentado, la autoconciencia pre-reflexiva es correlativa a la experiencia del mundo y del si mismo/a estando en el mundo, involucrado/a en el mundo, sin distancia narrativa, viviendo el mundo tácitamente en primera persona. En la autoconciencia pre-reflexiva la experiencia es dada como experiencia subjetiva, no como objeto de la experiencia. Es decir, esta autoconciencia pre-reflexiva es intrínseca a la propia experiencia de las cosas; puedo experimentar $\mathrm{x}, \mathrm{y}$ o $\mathrm{z}$; pero en todos los casos junto a $\mathrm{x}, \mathrm{y} \mathrm{o} \mathrm{z}$ tengo a la vez una experiencia de mi como sujeto de la experiencia, aunque sea en un plano subsidiario, tácito o, como se dice en fenomenología, pre-reflexivo. Esta autoconciencia corpórea pre-reflexiva tiene valor de evidencia en el sentido de que, si yo siento un cosquilleo en el brazo, por poner un ejemplo, es evidente de un modo inmediato que siento ese cosquilleo y que siento el brazo como "mi" brazo. En este punto no es posible equivocarse. Somos conscientes de nuestras experiencias vividas aún sin dirigir la atención hacia ellas. Así somos conscientes de nosotros mismos en el modo implícito de la experiencia en primera persona. La autoconciencia pre-reflexiva, por tanto, es una característica intrínseca de la experiencia del mundo. Es el trasfondo de toda experiencia. Esta forma primordial de autoconciencia nos da un componente de familiaridad con uno mismo como sujeto de la experiencia. En otras palabras, las experiencias que estoy viviendo son mías, las tengo yo. Este carácter de mías de las experiencias vividas, de la primera persona, es lo que el fenomenólogo D. Zahavi (2014) ha denominado el sentido mínimo del si mismo (ver también Fuchs, 2018).

Esta familiaridad con nosotros mismos como sujetos de la experiencia no se conoce a si misma como un objeto, sino como dijimos antes de un modo subsidiario, al tratar con el mundo. Este nivel de la experiencia ha sido descrito como un río o corriente de conciencia, un dinamismo de cambio continuo. Sostenidos por la tradición en forma de cultura y por el ámbito intersubjetivo, en la cotidianidad de la vida, pasamos de una cosa a otra sin aparente discontinuidad, siendo conscientes 
de nosotros mismos y del mundo sin problemas a no ser que algo se presente como un obstáculo o problema. La autoconciencia pre-reflexiva es el sujeto de la experiencia de primera mano, por decirlo así y en este sentido, se basta a si misma. A la vez, sirve de infraestructura o fundamento a la conciencia reflexiva. Para ello hace falta centrar la atención, de un modo intencional. Al hacer esto, lo que antes pasaba desapercibido, ahora se intensifica. Se ilumina con el haz de luz de la atención.

La conciencia reflexiva es la conciencia explícita, intelectual, conceptual y normal en la que estamos en el mundo compartido con otros, con el nivel de referencia normal que se tiene al compartir una realidad intersubjetiva (Pérez Álvarez, 2012). La autoconciencia pre-reflexiva puede tornarse autoconciencia reflexiva cuando toma algún aspecto de si misma como objeto de atención o análisis. De este modo, la conciencia pre-reflexiva o tácita puede ser examinada de manera reflexiva o explícita. Somos capaces de atender a nuestra propia experiencia y convertirla en objeto de atención. Así, la autoconciencia reflexiva puede desvelar, clarificar o hacer explícitos los elementos y estructuras que constituyen el funcionamiento normal de la experiencia de ser uno/a mismo/a y estar en el mundo. Cuando esto se lleva a cabo, se lleva a cabo también un desdoblamiento de la autoconciencia que no se producía en el nivel de la autoconciencia pre-reflexiva. Este desdoblamiento, a su vez, puede plantearse en diversos grados desde un estado de disociación patológica a un estado de distanciamiento reflexivo o terapéutico.

La autoconciencia reflexiva nos proporciona la vida examinada, reflexionada, tematizada. Debido a la estructura temporal de la experiencia, la autoconciencia reflexiva siempre sucede después de la autoconciencia pre-reflexiva que, como ya se ha dicho, nos da la vida en directo, vivida en tiempo real. Es importante darse cuenta de que entre la experiencia vivida y la experiencia reflexionada hay una distancia temporal y también narrativa. Siempre hay una pérdida en el momento reflexivo frente al momento vivido, como es natural, como nos recordaba J. L. Borges a través del relato de "Funes el memorioso". Este personaje tenía la extraordinaria capacidad de recordar todo lo vivido. El problema que tenía era que para recordar lo que había hecho en un día, necesitaba otro día entero. Por tanto, es bueno recordar que siempre hay una distancia entre lo vivido y lo comprendido y que la vida siempre va por delante. No somos completamente transparentes para nosotros mismos. Y como nos recuerda el profesor Pérez Álvarez (2012), para vivir como seres humanos completos, no nos hace falta la auto-transparencia.

También es posible ser autoconsciente de uno/a mismo/a en exceso. Uno o varios aspectos concretos de uno/a mismo/a (un pensamiento, sentimiento, sensación o recuerdo, un rasgo o una característica del propio cuerpo) pueden tornarse en objetos de una atención excesiva, hasta el punto de que aspectos implícitos en el funcionamiento normal pueden hacerse explícitos e interrumpir el desarrollo normal de una actividad. Por ejemplo, a medida que escribo, mi mente va seleccionando las palabras que mejor se ajustan a la idea que quiero comunicar; al 
hacer esta tarea, de un modo automático y en su mayor parte inconsciente, mi mente integra la actividad de varias subunidades cognitivas, referidas al léxico, la gramática, la jerarquía entre las frases, etc. Si estas rutinas cognitivas subpersonales accedieran al nivel de mi conciencia, no podría escribir dos frases seguidas. El nivel de distorsión sería intransitable. Cuando se produce esta presencia distorsionadora y cuando la reflexividad deja de ser un mecanismo para solucionar problemas y se convierte ella misma en un problema por su excesiva presencia, entonces se habla de hiper-reflexividad. De un modo u otro, algún tipo de autoconciencia hiper-reflexiva está en la base de los distintos trastornos psicológicos como veremos más tarde.

Las nociones de autoconciencia pre-reflexiva, reflexiva e hiper-reflexiva resultan importantes para comprender los ejes dentro de los cuales se puede mover la reconstrucción terapéutica de la experiencia vivida. Pero también es importante tener presente el contexto cultural en la que la conciencia se encuentra inserta.

\section{Una nueva ecología de la mente}

A principios de los años 70, Gregory Bateson, uno de los padres del enfoque sistémico, publicó un texto denominado "Pasos hacía una ecología de la mente". Bateson no fue un terapeuta, sino un pensador, en el sentido clásico de la palabra, que hizo contribuciones relevantes en los campos de la antropología, la psiquiatría, la biología y la epistemología. En el contexto de este texto, la palabra ecología, proveniente de la biología, se utilizaba como una extensión metafórica para hacer referencia al ambiente relacional en el que la mente se encuentra inserta. Pero este ambiente relacional era complejo y abarcaba múltiples niveles. A modo de ejemplo de su pensamiento, Bateson escribe: "podemos decir que "la mente" es inmanente en aquellos circuitos del cerebro que están completos dentro del cerebro. O que la mente es inmanente en los circuitos que están completos dentro del sistema, cerebro más cuerpo. O, finalmente, que la mente es inmanente en el sistema más ampliohombre más ambiente" (Bateson, 1972, p. 317). En la actualidad, T. Fuchs, un psiquiatra, filósofo y clínico de la Universidad de Heilderberg que ocupa la cátedra Karl Jaspers, ha publicado una visión del cerebro como un órgano de mediación, transformación y resonancia, que resulta enormemente útil para contrarrestar las posiciones cerebro-centristas, tan reduccionistas como dominantes en la neurociencia actual. En esta publicación, Fuchs (2018) rinde homenaje a Bateson titulando su texto "Ecology of the brain".

Un par de años antes de la publicación del libro de G. Bateson, N. Postman, un lingüista de la Universidad de Nueva York y admirador de la obra de M. McLuhan, acuñó el término media ecology o ecología de los medios de comunicación. Con esta expresión intentaba acotar un vasto campo de estudio interdisciplinar cuyos pilares principales serían las obras de M. McLuhan (1964/2009), E. Havelock (1986/1996) y W. Ong (1982/1996), entre otros. En este marco, por "ecología de los medios" se entiende el estudio de los sistemas de comunicación como ambientes. 
Es decir, el foco de atención no recae tanto en el medio de comunicación, como por ejemplo la TV, ni siquiera en su técnica o tecnología, sino en la manera en que la interacción entre los medios y los seres humanos da lugar a una cultura y a una manera de utilizar los sentidos y los procesos cognitivos. Esta perspectiva de la ecología de los medios de comunicación ha servido para mostrar cómo las tecnologías que afectan al lenguaje modifican la conciencia, como escribió W. Ong (1982/1996).

Los estudios de E. Havelock sobre el lenguaje de los pre-socráticos, junto con los trabajos de M. Parry (1971) sobre los textos homéricos, más los estudios de W. Ong sobre la memoria oral y los de M. McLuhan sobre la imprenta, entre otros, sirvieron para poder de manifiesto cómo las tecnologías que afectan al lenguaje transforman la conciencia; es decir, los cambios que afectan a cómo nos comunicamos con los demás, afectan también a nuestros procesos sensorio-motores y cognitivos (ver Miró, 2014). Por ejemplo, en un mundo oral, en las condiciones de las sociedades que desconocen por completo la escritura, el sensorium - es decir, la organización de los sentidos que sirve de fundamento a la conciencia- funciona de manera diferente a las sociedades que disponen de escritura. El nivel conceptual de la mente está ausente.

La experiencia del mundo, de los demás y de si mismo/a es completamente diferente en un mundo gobernado por la oralidad versus un mundo gobernado por la escritura. En un mundo oral, el sentido auditivo es dominante respecto al resto de los sentidos; el sensorium (la Gestalt que forman los sentidos en su interacción o la unidad sensorio-motora) funciona en clave auditiva. El espacio acústico se percibe por medio de sonidos y ecos. El sonido es envolvente, porque los sonidos se perciben como provenientes de todas las direcciones, de modo que el oyente se siente situado en el centro de su espacio acústico. Como ningún otro sentido, el sonido permite un tipo de inmersión total en el que la dualidad sujeto-objeto desaparece. Además, el sonido carece de soporte material y es evanescente. A W. Ong le gustaba explicar esta característica por medio de una paradoja y decía: “El sonido sólo existe cuando deja de existir". Por ejemplo, cuando pronuncio la palabra "meditación", cuando llego a "ación", "medit" ha dejado de existir y se ha perdido; sólo permanece en el breve espacio de la memoria a corto plazo. Los sonidos sólo existen en el mundo real, en el ahora y sólo existen si algo los produce. La experiencia auditiva es holista e integradora. Escuchamos de una vez, como una totalidad. Y aunque los sonidos provengan de distintas direcciones y sean dispares, pueden ser conjuntados de un modo armónico.

Cuando se expandió el alfabeto griego - proceso que en la Grecia clásica duró más de trescientos años, los que median de Homero a Platón-, el sensorium (la Gestalt intermodal o la organización sensorio-motora), que está en la base de la conciencia, cambió de clave auditiva a clave visual. Las palabras, que Homero había llamado "aladas" porque eran fugaces como el viento, al ser escritas, se convirtieron en objetos visuales. El observador podía situarse ante ellas con cierta distancia, 
transcendiendo la inmediatez de la experiencia. Podía distinguir la palabra como objeto de su significado. Podía comparar, abstraer o descontextualizar. En definitiva, podía pensar en términos de formas ideales como el mundo de las ideas de Platón. Este cambio hizo posible la emergencia de la noción de mente, el mundo conceptual, el razonamiento discursivo, el poder del silogismo, la separación psicológica del individuo del grupo, etc. En síntesis, hizo posible la emergencia de la dualidad observador-observado o sujeto-objeto (Miró, 2014).

No se trata aquí de seguir profundizando en cómo la escritura re-estructuró la conciencia humana. El propósito de estas notas es únicamente mostrar la fertilidad de la investigación en la que las tecnologías de la comunicación concebidas como ambientes se cruzan con el estudio de los procesos cognitivos. Desde el punto de vista de la ecología de los medios, se suelen distinguir tres etapas bien diferenciadas: La primera sería la oralidad primaria, que mostraría la conciencia en estado prístino, la segunda hace referencia a la escritura, por un lado, y a la imprenta por otro, y la tercera haría referencia a la comunicación electrónica. No es posible, sin embargo, en el espacio de este texto seguir los cambios cognitivos ni las transformaciones en la conciencia implicadas en cada una de estas etapas. Pero, no obstante, no se puede dejar de señalar ciertos aspectos de la ecología de los multimedia de la actualidad.

Bajo el epígrafe de "comunicación electrónica", se suelen agrupar los medios de comunicación surgidos del maridaje del lenguaje con la electricidad. Con ellos, la información viaja a la velocidad de la luz. Históricamente, el primer medio electrónico fue el telégrafo, que permitió el procesamiento electrónico de la palabra escrita. Siguió el gramófono, que permitió la reproducción de música; el teléfono permitió la comunicación electrónica de la palabra hablada, al igual que la radio había permitido la escucha electrónica. El cine supuso el procesamiento electrónico de las imágenes visuales silenciosas primero y sonoras, después. A continuación, todo ello penetró en los hogares por medio de la TV, produciendo una "colonización" masiva y sin precedentes de la mente humana. Un poco más tarde llegaron los computadores y los ordenadores personales, Internet, la telefonía móvil y la realidad virtual. Esta progresión resulta, en efecto, vertiginosa. No obstante, resulta importante no olvidar que la emergencia de un nuevo medio no significa la desaparición de los anteriores. Al contrario, los nuevos medios interactúan con los antiguos de maneras complejas y con frecuencia impredecibles.

$\mathrm{Si}$ los medios de comunicación son extensiones de los sentidos, como decía M. McLuhan, resulta evidente que, a esta nueva ecología multimedia, corresponde un nuevo sensorium. De hecho, este autor hablaba de la comunicación electrónica como si fuera un sistema nervioso extendido. Esta metáfora, que también se ha utilizado para describir Internet, ayuda a visualizar la humanidad como una totalidad, como los habitantes de la aldea global. Para comprender este nuevo sensorium constituido por los medios entendidos como prolongaciones de los sentidos, conviene tener presente que cuando se aprende a manejar un medio, éste tiende a hacerse transparente, de modo que lo pasamos por alto. Tendemos a fijarnos 
en los contenidos y tendemos a olvidar el medio, en el que apenas reparamos. Para ilustrar esta situación, sirva la siguiente anécdota: Un colega de la isla de Lanzarote, me contó que cuando la TV llegó a su casa se quedaron todos encantados y como hipnotizados con el aparato hasta que se hizo la hora de cenar y todos en la familia se trasladaron a la cocina, menos la abuela que seguía en la sala mirando la TV. Al ir a pedirle que acudiera a cenar con los demás, ella contestó: "no puedo". Y "por qué no puedes" -replicó mi colega. "Pues, porque no puedo dejar a este hombre hablando solo" - contestó la abuela.

¿Cuál es el estatus ontológico de las imágenes de las pantallas? Parece claro que la abuela de mi colega le estaba otorgando un tipo de realidad al presentador de las noticias que veía en la pantalla diferente de la realidad que le otorgaba mi colega. Para ella, el presentador, aunque estuviera en la pantalla, estaba presente en la sala de una manera real, y ella también estaba presente de un modo real, por eso no podía permitirse no escucharlo. En cambio, para mi colega el presentador estaba ausente y el mismo también estaba ausente, podía ir a hacer otra cosa. El presentador no era más que una imagen en una pantalla, una representación. No era real. Sólo era como si fuera real.

La realidad mediada por los medios tiene un estatus ontológico ambiguo. Anders (1956/2011), filósofo alemán (alumno de M. Heidegger y coetáneo de H. Arendt con quien estuvo casado) y testigo de los cambios experimentados por la sociedad estadounidense al introducir la radio y la TV en los hogares, analizó este carácter ambiguo llamándolo fantasmagórico: "Porque las imágenes están a medias presente y ausente, o sea, como un fantasma" (p. 118). En su penetrante análisis, Anders sostenía que el continuo consumo de imágenes suministradas por los medios dejaría a los seres humanos sin referencias, sin mundo y completamente dispersos; se convertirían en "meros contemporáneos del ahora". En un contexto diferente y más actual S. Turkle (2011) ha estudiado también los cambios en los modos de vida producidos por el consumo de las nuevas tecnologías y ha enfatizado lo que ha llamado "cultura de la simulación" (p. 4), en la que la diferencias entre lo natural y lo artificial, el cuadro original y la copia o entre la realidad y la ficción, se hacen cada vez más borrosas.

Esta diferencia entre la "realidad real", por decirlo así, versus la "realidadficción" resulta extraordinariamente importante en el mundo actual, porque el consumo de imágenes ha adquirido proporciones inimaginables. A diferencia de los animales, los seres humanos poseemos la capacidad de dudar de las cosas que existen e imaginar cosas que no existen. La imaginación y la posibilidad de pensar de manera contra-factual, lo que J. Bruner llamaba "construir mundos en subjuntivo” - ¿qué pasaría si x fuera y?”, “ ¿cómo actuaría si se diera la condición z?”, etc.- forman parte de la intersubjetividad humana y es constitutiva de la manera en que contamos historias y construimos un mundo compartido con otros reales. No obstante, cuando fantaseamos o imaginamos somos conscientes de que estamos fantaseando o imaginando. 
La clave de esta construcción de mundos de ficción y fantasía reside en la capacidad intersubjetiva humana de actuar como si, que desarrollamos desde la infancia por medio del juego. Por ejemplo, cuando un niño utiliza un plátano para hablar por él como si fuera un teléfono. Esta capacidad de suspender la realidad del plátano como plátano y utilizarlo como teléfono porque su forma facilita o permite (affords) este uso, se encuentra en el origen del juego y también de la empatía y de la capacidad de contemplación estética. Por ejemplo, en el arte pictórico se habla de "diferencia icónica" para hacer referencia a la diferencia entre la pintura como un objeto en el mundo versus el mundo dentro de la pintura y somos conscientes de los dos modos de realidad simultáneamente. De la misma manera, cuando percibimos una película como una película, percibimos su contenido como si fuera real. Coleridge, el poeta inglés, acuño la fórmula de "fe poética" o "suspensión voluntaria de la incredulidad" para explicar cómo disfrutamos de la ficción. Aceptamos creer en la realidad de lo que se cuenta dentro de los límites del relato, sabiendo que una vez que el relato acabe nos encontraremos nuevamente con la realidad habitual. Esta suspensión voluntaria de la incredulidad la ponemos en práctica cada vez que interactuamos con la ficción; por ejemplo, al ver una película con Penélope Cruzpor poner un ejemplo- aunque la veamos a ella, suspendemos este reconocimiento para creernos que es el personaje que interpreta; si no fuera así, si en lugar del personaje viéramos al actor real, no podríamos disfrutar de las películas.

La empatía real implica también un componente de conciencia desplegada, dividida o conciencia como si; por ejemplo, ponerse en los zapatos del otro, como se dice en la Biblia, no significa convertirse en el otro, sino comprenderlo como si se fuera el otro, permaneciendo, a la vez, consciente de la diferencia, es decir, de que no se es el otro. Fuchs (2014) ha explicado la importancia de esta consciencia dividida implicada en la conciencia como si en la empatía real: "Para interactuar con los demás, se debe ser capaz simultáneamente de alternar y diferenciar entre la propia perspectiva corpórea y la perspectiva virtualmente imaginada del otroi.e. se debe ser capaz de afirmarse a uno mismo frente al otro. Si esta conciencia dividida se rompiera, entonces daría lugar a una empatía casi sin límites en la que el sujeto se perdería a si mismo al percibir al otro" (Fuchs, 2014, p. 163).

Antes de la invasión de los multimedia, la capacidad de virtualización se encontraba limitada a los espacios o tiempos de juego, que se contraponían a las esferas de la realidad habitual. Pero en la actualidad, la virtualización satura cada vez más todas las esferas de la vida cotidiana, invadiendo el espacio del trabajo y también el espacio de las relaciones personales y familiares. Por un lado, se corre el riesgo de la dispersión y la banalización, es decir, perder de vista las propias prioridades y lo que realmente vale la pena, como señalaba Anders. Pero, por otro lado, la presencia de los nuevos medios de la comunicación electrónica es tan invasiva que no resulta exagerado decir que han transformado la materialidad de nuestro mundo y han transformado también nuestra manera de pensar sobre nosotros mismos y sobre los demás. Como decía M. McLuhan, "modelamos 
nuestras herramientas y después nuestras herramientas nos modelan a nosotros". V. Sobcback, una destacada crítica y fenomenóloga del cine, al explorar el impacto del cine sobre los hábitos de la sociedad estadounidense, señalaba lo siguiente:

“... todos somos parte de una cultura de imágenes en movimiento y vivimos vidas cinematográficas y electrónicas. De hecho, no es una exageración sostener que ninguno de nosotros puede escapar de los encuentros diarios -tanto directos como indirectos- con los fenómenos objetivos de las tecnologías fotográficas, cinematográficas, televisivas, computacionales, las redes de comunicación y los textos que producen. Tampoco es una exageración sugerir que, de la manera más profunda, socialmente persuasiva y aun así personal, estos encuentros objetivos nos transforman como sujetos encarnados" (Sobcback, 2004, p. 136).

Es una realidad hoy todavía más que hace 15 años, cuando Sobcback escribía este texto, que vivimos en la ecología creada por estas nuevas materialidades tecnológicas de la fotografía, el cine, la televisión, los computadores, las redes sociales virtuales, Internet, los teléfonos móviles y la realidad virtual. Pero ¿qué significa afirmar que vivimos vidas cinematográficas?

Significa varias cosas: Por un lado, el cine ha sido y es un poderoso instrumento para configurar mentalidades e influir en la forma de pensar y comportarse de las personas. Además, como hemos señalado antes, esta forma de influencia ocurre cuando el espectador ha entrado en un estado no crítico, el modo de "fe poética" del que se hablaba antes, es decir de suspensión de la incredulidad. Conocemos muchas realidades no de primera mano, sino porque las hemos visto en el cine. Por ejemplo, tal vez no hemos sufrido nunca un desengaño amoroso profundo; pero podemos reconocerlo porque lo hemos visto en el cine.

La pantalla de cine ha sido comparada en numerosas ocasiones con la corriente de conciencia. Se ha visto en la pantalla una ventana abierta al mundo, como si fuera una extensión de nuestros sentidos. Una ventana por la que nos llegan tiempos históricos no vividos, experiencias emocionales y afectivas no sentidas, lugares geográficos no conocidos, etc. El mismo cine nos ofrece una magnífica reflexión sobre su influencia y poder de seducción, en la película "Cinema Paraiso". El tema de la película es el impacto del cine en un pueblo de la Italia rural de la post-guerra a través de los ojos de un niño. Uno de los personajes centrales es el párroco del pueblo que intenta evitar que los jóvenes queden contaminados por las películas sensuales de los estadounidenses liberales, a las que los jóvenes quieren acudir a cualquier precio porque en esas películas aprenden nuevas formas de besar. El entrañable protagonista de la película, el niño Toto, recorta y colecciona fotogramas y a través de esos fotogramas juega a imaginar la película entera. El cine no sólo es una ventana abierta a la realidad, sino también, y de un modo muy relevante, es una ventana abierta a otros mundos posibles.

Para que funcione como comunicación, el cine no sólo requiere la implicación del espectador, requiere también de una sofisticada tecnología para presentar las 
escenas como si fueran reales. Por lo general, el espectador no repara en los cortes en los planos, las angulaciones, los planos secuencia, las panorámicas, ... entre otros recursos narrativos inventados por los directores de cine durante su siglo de existencia. El cine, además de una ventana, es un filtro en el que la cámara impone un punto de vista y una interpretación a partir de lo que el director quiere comunicar. Y como en toda comunicación, no sólo cuenta lo que se dice; también cuenta lo que no se dice. Un encuadre puede "mentir" no tanto por lo que muestra, sino por lo que deja fuera (Orellana, 2017).

Es indudable que, en sus más de cien años de historia, el cine se ha desarrollado tecnológicamente de un modo fascinante. Y paralelamente los espectadores también hemos ido educando nuestros ojos y actitudes para ver cine. Cada vez estamos más lejos del realismo ingenuo de la abuela de mi colega de la isla de Lanzarote que tomaba las imágenes de la pantalla como si fueran reales. Pero, a la vez, cada vez es mayor el consumo de imágenes, de una realidad ya construida o mediada por las pantallas y un consumo excesivo de esta realidad mediada podría disolver las fronteras entre la realidad y la ficción y podría también fomentar la visión del mundo como una proyección de la propia mente. Por una razón simple, cuando se escucha a un orador en la situación cara a cara se está en la compañía del orador, sin embargo, el lector de novelas y el consumidor de imágenes en las pantallas está sólo.

Para concluir, en este apartado hemos expuesto cuestiones relevantes para trabajar terapéuticamente con la técnica de la moviola. La primera cuestión que expusimos tenía que ver con comprender la cognición corporeizada o encarnada. Como indica Fuchs (2018) esta perspectiva ayuda a ver el debate clásico de cuerpomente de un nuevo modo: Si la mente está corporeizada el debate no es entre una entidad material (sustancial) versus una entidad no-material (insustancial), sino que lo que hay es cuerpo versus cuerpo, es decir, el cuerpo como sujeto versus el cuerpo como objeto. Sobre este plano se estableció la distinción entre autoconciencia prereflexiva, reflexiva e hiper-reflexiva. Por último, se aportaron algunas ideas sobre la nueva ecología multimedia en el que está inserta la actividad humana actual y también sobre la relevancia que el cine ha adquirido en nuestras nuevas "vidas cinematográficas".

\section{Parte II, Práctica: Ejemplo de Uso de la Moviola en un Caso Clínico}

En este apartado, se expone una viñeta clínica con el propósito de ilustrar el tipo de trabajo que se puede llevar a cabo con la técnica de la moviola en psicoterapia.

María es una paciente de 25 años que es remitida por su médico de cabecera a la consulta después de que rechazara seguir trabajando con otra terapeuta tras 4 sesiones con ella. Es hija única y sus padres son agricultores y tienen un nivel cultural más bien bajo. El problema principal de María tiene que ver con su rechazo a la comida por miedo a engordar. Ha perdido peso, pero su situación no es dramática. Cuando se le pregunta porqué dejó de trabajar con la terapeuta anterior 
dice que porque no la entendía, sin querer ofrecer más detalles. Tampoco sabe relatar con precisión cuándo empezó su decisión de reducir su ingesta. De un modo confuso, cuenta que unos meses antes había decidido dejar de trabajar debido a las discusiones con su supervisora. Estaba empleada como camarera de hotel. No ha vuelto a buscar trabajo y permanece en su hogar. Tampoco tiene interés en buscar un trabajo, porque va a casarse - según refiere en la primera sesión. Ante esta inesperada revelación, la terapeuta decide centrar la conversación en la relación con el novio. Se argumenta esta decisión con la paciente más o menos del siguiente modo: "Como la boda va a suponer un cambio de vida importante para ti, ¿no crees que sería buena idea examinar cómo te sientes en la relación con tu novio y con tu boda futura?". Ella consiente en centrar la conversación en las próximas sesiones sobre esta cuestión. En la siguiente sesión, se abordan los aspectos de la relación con el novio que era un chico del pueblo, que había ayudado a su padre en las tareas del campo y que era conocido y aceptado por su familia. Cuando se indaga acerca de cómo llevaban a cabo su noviazgo, la paciente ofrece poca información; no obstante, no resulta difícil deducir que no han tenido relaciones sexuales y que no ha sucedido nada entre ellos que no pudiera ser aprobado por sus padres. Poco a poco, sin forzar su ritmo, la paciente se va abriendo a hablar acerca de su relación.

En la siguiente sesión, la terapeuta decide indagar con la ayuda de la moviola. La paciente ha referido una situación en la que ella y su novio estaban pasando la tarde del sábado en el piso que había encima de la casa de sus padres y que disponía de una escalera interior que comunicaba ambas estancias. La visión panorámica inicial de aquella tarde que ofrece la paciente es la siguiente: Han pasado la tarde viendo la TV y han cenado en una habitación conjunta a la sala de la TV. Entonces, la terapeuta le propone a la paciente indagar sobre este episodio con mayor profundidad diciendo algo así como lo siguiente: "A veces, para saber bien lo que nos pasa, conviene pararnos y reflexionar sobre cómo hemos vivido una situación concreta. Cuando reflexionamos, lo que hacemos es, en cierto modo, parecido a lo que hacen en el futbol cuando vuelven a pasar la situación de dio lugar al penalti a cámara lenta, como si las escenas fueran puestas en una moviola. ¿Te parece bien que yo te ayude a revisar lo que pasó esa tarde del sábado para ver qué podemos aprender?"

Después de que la paciente diera su consentimiento, la terapeuta empezó a guiar a la paciente para que relatara la situación como si hubiera sido filmada y ahora pudiéramos verla en una pantalla de TV. Hacer esto requiere que la paciente describa la situación desde un punto de vista externo, describiendo las estancias, el mobiliario y cómo estaban situados en la escena. Para el terapeuta, este trabajo de guiar al paciente a ver la situación desde el exterior es similar a lo que haría un director de cine en la parte de puesta en escena de los actores. A su vez, para el paciente hacer este trabajo de verse desde fuera requiere un esfuerzo cognitivo grande y también requiere de un soporte en el que fijar la vista y de la ayuda del terapeuta. Una vez se ha articulado y explorado la escena desde el exterior en todos 
sus detalles relevantes, se procede a ayudar al paciente a cambiar el punto de vista hacia el interior; es decir, a lo que sólo era accesible para ella desde dentro, lo que se denomina datos de la autoconciencia privada; desde ahí, se le pregunta por sus emociones, sensaciones o pensamientos presentes en la situación. Por lo general, se nota cuándo los pacientes recuerdan la situación y se sitúan dentro de ella, porque la atención se retira hacia el interior. En este punto conviene ofrecer un soporte, como una pared o una pantalla apagada o incluso la propia mano del terapeuta, en el que puedan fijar la vista mientras interiormente re-estructuran la escena vivida.

Siguiendo con la revisión de aquella tarde con la paciente, a continuación, se exploró cómo ella había ido al piso de abajo a recoger la bandeja con la cena que la madre había preparado. En la bandeja había un plato con lechuga para ella y, para el novio, un cuenco con sopa y un plato con pollo y patatas fritas. Subió la bandeja al piso de arriba por la escalera interior con sumo cuidado para que la sopa no se derramara y se sentaron a cenar. Al ver esta escena desde el exterior aparecían varios niveles en paralelo; por un lado, se pudo fijar el contenido de la conversación que giraba en torno al tema de poner a prueba al novio; ella le hacía preguntas del tipo, "y si no me curo y sigo así, ¿tú seguirás queriéndome?". Mientras él se terminaba la sopa, le aseguraba que si que él la seguiría queriendo. En ese punto, ella ya había terminado su plato de lechuga. Y seguíamos explorando la escena desde fuera. Entonces, la terapeuta le pidió que le dijera qué era lo que ella veía que estaba haciendo al verse desde fuera. Y, sin dudar un segundo, ella contestó: "estaba mirando las patatas fritas de su plato". A partir de aquí, cuando se vio en la pantalla imaginaria de su recuerdo y se reconoció mirando las patatas fritas del plato del novio, reconoció también sus ganas de comerse esas patatas y cómo en la situación las había inhibido con mucho esfuerzo, porque después de comerse las hojas de lechuga de su plato, se había quedado con hambre - según pudo darse cuenta en la sesión. Llevar a cabo esta revisión de la escena fue arduo y, en gran medida, tedioso, tanto para la paciente que no estaba acostumbrada e revisar una escena vivida con este nivel de detalle, como para la terapeuta que tenía que reconducir la atención de la paciente hacia la situación que estaba siendo reconstruida, a la vez que respetaba su ritmo.

Este trabajo de minuciosa reconstrucción de la experiencia vivida en el nivel de la autoconciencia pre-reflexiva, hubiera pasado desapercibido si no hubiera sido porque en la sesión siguiente la paciente mostró una completa remisión de su sintomatología. Llegó a la sesión diciendo que aquella iba a ser su última sesión, porque se había dado cuenta de que lo que estaba haciendo era una tontería. Dijo, además, que había tomado la decisión de limitar su ingesta el día que vio llegar el camión con los materiales para construir la casa, al lado de la de los padres, en la que iba a vivir con el novio con el que iba a casarse. Como ella misma dijo, ver aquel camión le llevó a darse cuenta de que la situación de compromiso con el novio no tenía vuelta atrás y eso le dio miedo. Pero ahora se había dado cuenta de lo que pasaba y ya no le daba miedo y quería seguir adelante con su boda. 
De algún modo, lo que la paciente narró en esta última sesión ya lo sabía. Pero actuaba como si no lo supiera. Con la ayuda de la moviola guiada por la terapeuta pudo ir reconociendo niveles de sus experiencias que antes inhibía o ignoraba por miedo y, en cambio, después de la terapia, podía aceptar y reconocer.

\section{Conclusiones}

Es evidente que queda mucho trabajo por hacer para fundamentar bien la técnica y también para describirla de un modo estructurado como un procedimiento cuyos efectos puedan ser conocidos y replicados. Sirvan estas páginas como adelanto de ese trabajo futuro. También vale la pena mencionar que, para manejar la técnica con destreza, es necesario contar con formación específica. Así mismo, conviene indicar también que esta técnica puede ser integrada con éxito en distintos marcos conceptuales. La moviola ofrece un soporte técnico para llevar a cabo el trabajo terapéutico. Pero, en ningún caso, sustituye ese trabajo.

\section{Referencias bibliográficas}

Anders, G. (2011). La obsolescencia del hombre, sobre el alma del hombre en la época de la segunda revolución industrial. Valencia, España: Editorial Pretextos (Trabajo original publicado en 1956).

Bateson, G. (1985). Pasos para una ecología de la mente. Buenos aires, Argentina: Lohlé-Lumen (Trabajo original publicado en 1972).

Beck, A. T. (1976). Cognitive Therapy and the Emotional Disorders. Nueva York, NY: Penguin Books.

Borges, J. L. (1944). Funes el memorioso. En J. L. Borges (Ed.), Ficciones. Buenos Aires, Argentina: Sur.

Ellis, A. (2017). Una nueva guía para una vida racional. Madrid, España: Obelisco. (Trabajo original publicado en 1961).

Fuchs, T. (2014). The virtual other, empathy in the age of virtuality. Journal of Consciousness Studies, 21(5-6), 15273.

Fuchs, T. (2018). Ecology of the Brain. Oxford, Reino Unido: Oxford University Press.

Guidano, V. (1987). Complexity of the Self. Nueva York, NY: Guilford.

Guidano, V. (1990). De la revolución cognitive a la intervención sistémica en términos de complejidad: la relación entre teoría y práctica en la evolución de un terapeuta cognitivo. Revista de Psicoterapia, 1(2-3), 113-129. Recuperado de: https://bit.ly/2VXleAm

Guidano, V. (1991). The self in process. Nueva York, NY: Guilford.

Guidano, V.y Quiñones, A. (2018). El modelo cognitivo post-racionalista. Hacia una reconceptualización teórica y clínica. Bilbao, España: Desclée de Brower (Trabajo original publicado en 2001).

Harari, Y. N. (2018). XXI lecciones para el s. XXI. Madrid, España: Ed. Debate

Havelock, E. (1996). La musa aprende a escribir. Barcelona, España: Paidós. (Trabajo original publicado en 1986).

Hayes, S. (2004). Acceptance and Commitment Therapy and the New Behavior Therapies: Mindfulness, Acceptance, and Relationship. En S. Hayes, V. M. Follette y M. Linehan, (Eds.), Mindfulness and Acceptance, expanding the cognitive-behavioral tradition (pp.1-29). Nueva York, NY: Guilford.

James, W. (1994). Principios de Psicología. México, México: Fondo de Cultura Económica. (Trabajo original publicado en 1890).

Johnstone, L., Boyle, M., Cromby, J., Dillon, J., Harper, D., Kinderman, P., Longden, E., Pilgrim, D. y Read, J. (2018). The Power Threat Meaning Framework Overview. Leicester, Reino Unido. British Psychological Society. Recuperado de: www.bps.org.uk/PTM-Main

McLuhan, M. (2009). Comprender los medios de comunicación. Barcelona, España: Paidós (Trabajo original publicado en 1964).

Mead, G. H. (1968). Espíritu, Persona y Sociedad. Buenos Aires, Argentina: Paidós (Trabajo original publicado en 1934). 
Miró, M. T. (2012). Mindfulness y auto-observación terapéutica. En M. T. Miró y V. Simón (Eds.), Mindfulness en la práctica clínica (pp. 5-35). Bilbao, España: Desclée de Brower.

Miró, M. T. (2014). Dal Sé scisso all'attenzione piena. En A. Quiñones Bergeret, P. Cimbolli y A. De Pascale(Eds.), La psicoterapia dei proccessi di significato personale dei disturbi psicopatologici (pp. 391-406). Roma, Italia: Alpes.

Ong, W. J. (1996). Oralidad y escritura. La “tecnologización” de la palabra. México, México: FCE (Trabajo original publicado en 1982).

Orellana, J. (2017). Fundamentos de narrativa audiovisual. Madrid, España: CEU ediciones.

Parry, M. (1971). The making of homeric verse. The collecterd pappers of Milman Parry. Oxford, NY: Oxford University Press.

Pérez Álvarez, M. (2012). Las raíces de la psicopatología moderna. Madrid, España: Pirámide.

Polanyi, M. (1958). Personal Knowledge, toward a post-critical philosophy. Chicago, IL: University of Chicago Press.

Sass, L. A. (2014). Locura y Modernismo, la esquizofrenia a la luz del arte, la literatura y el pensamiento modernos. Madrid, España: Ediciones Dykinson (Trabajo original publicado en 1992).

Sobcback, V. (2004). Carnal Thoughts: Embodiment and Moving Image Culture. Los Ángeles, LA: University of California Press.

Stern, D. (1991). El mundo interpersonal del infante. Una perspectiva desde el psicoanálisis y la psicología evolutiva. Barcelona, España: Paidós (Trabajo original publicado en 1985).

Trevarthen, C. (2011). What is it like to be a person who knows nothing: Defining the Active Intersubjetive Mind of a Newborn Human Being. Infant and Child Develomnet, 20(1), 119-135. https://doi.org/10.1002/icd.689

Turkle, S. (2011). Alone together: why we expect more from technology and less from each other. Nueva York, NY: Basic Books

Varela, F. Thompson, E. y Rosch, E. (2017), The embodied mind. Cognitive Science and Human Experience. Boston, MA: MIT Press (Trabajo original publicado en 1991).

Zahavi, D. (2014). Self and Other: Exploring Subjectivity, Empathy and Shame. Oxford, Reino Unido: Oxford. 